\title{
DAÑoS TÓXICOS EN TEJIDOS VEGETALES, PRODUCIDOS POR AGUAS CONTAMINADAS CON ARSÉNICO EN ZIMAPÁN, HIDALGO, MÉXICO ${ }^{1}$
}

\author{
Francisco Prieto GARCÍA ${ }^{2, *}$, María de los Ángeles Lechuga VARGAS², María Aurora Méndez MARZO \\ Enrique Barrado ESTEBAN ${ }^{4}$, Juan Carlos Ggaytán OYARZÚN ${ }^{5}$
}

\section{RESUMEN}

Según estudios realizados en el periodo de 1992-1998 en las aguas de los pozos, norias y manantiales, del municipio de Zimapán, Estado de Hidalgo, México, se corroboró que existía un incremento en el contenido de arsénico rebasando los límites máximos permisibles por la Norma Oficial Mexicana. La determinación de arsénico en las muestras de aguas se realizó por absorción atómica (AAS), mediante generador de hidruros (GH). En este estudio se utilizó el Vicia faba como un bioensayo para evaluar el daño genotóxico con la prueba de inducción de micronúcleos por exposición al agua de Zimapán, contaminada con As en células de raíces. Se utilizó como ensayo de control un agua de pozo de similares características del municipio de Pachuca, pero con contenidos de As por debajo de los límites de detección. Los resultados mostraron que el agua de esta región presenta altas concentraciones de arsénico y que puede provocar efectos genotóxicos que se manifiestan por la inducción de micronúcleos en las células meristemáticas de raíces de tejidos vegetales sensible.

Palabras clave: arsénico, bioensayos, Vicia faba, toxicidad.

\section{RESUMO}

DANOS TÓXICOS EM TECIDOS VEGETAIS, PRODUZIDOS POR ÁGUAS CONTAMINADAS COM ARSÊNIO EM ZIMAPÁN, HIDALGO, MÉXICO. Estudos feitos no período de 1992-1998 nas águas dos poços da municipalidade de Zimapán, estado do Hidalgo, México, demostram o aumento na concentração de arsênio ultrapassando os limites máximos permissíveis pela norma oficial mexicana. A determinação de arsênio nas amostras de água foi feita por absorção atômica (AA), por meio do gerador de hidruros (GH). Neste estudo, o Vicia faba foi usado como bioensaio para avaliar os danos genotóxicos com o teste da indução dos micronúcleos pela exposição à água de Zimapán, contaminada com arsênio em células de raízes. Como controle, foi usada uma água com similares características, do município de Pachuca, mas com índices abaixo dos limites de detecção. Os resultados mostraram que a água desta região apresenta altas concentrações de arsênico e que os efeitos genotóxicos manifestam-se pela indução dos micronúcleos nas células meristemáticas de raizes de tecidos vegetais sensíveis.

Palavras-chave: arsênico, bioensaios, Vicia faba, toxicidade.

\section{1 - INTRODUCCIÓN}

La acumulación de metales pesados en sólidos, sedimentos y tejidos vegetales, bien sea por adsorción y/o coprecipitación u otras formas de asociación natural, incluida la bioacumulación, constituyen un modo de minimizar su transporte y propagación. Esto puede acarrear a largas consecuencias negativas para el entorno ecológico; variaciones del medio circundante a los sólidos y sedimentos pueden producir la lixiviación de cantidades significativamente elevadas de especies tóxicas y con ello se hacen accesibles a los sistemas acuosos y seres vivos. Su acumulación en tejidos vegetales puede llegar a producir daños genotóxicos en sus células y de esta forma, se incorporan al hombre por la cadena alimentaria [11].

\footnotetext{
${ }^{1}$ Recebido para publicação em 1/12/2004. Aceito para publicação em 23/1/2006 (001446)

${ }^{2}$ Centro de Investigaciones Químicas

${ }^{3}$ Centro de Investigaciones de Materiales y Metalurgia

${ }^{4}$ Departamento de Química Analítica, Facultad de Ciencias, Universidad de Valladolid, Valladolid, España

${ }^{5}$ Centro de Investigaciones Biológicas, Universidad Autónoma del Estado de Hidalgo, Carretera Pachuca-Tulancingo, km 4,5, C.P. 42076, Pachuca, Hidalgo México

A quem a correspondência deve ser enviada
}

La Gerencia Estatal de la Comisión Nacional del Agua en Hidalgo tiene conocimiento de la presencia de altos contenidos de arsénico en el agua que es suministrada por los pozos a la población de la ciudad de Zimapán. Un estudio sobre los contenidos de este elemento durante el periodo marzo 92marzo 93, confirmó que dichos pozos están contaminados con arsénico [2] y que rebasan los límites máximos permisibles por la Normativa Mexicana [9] (0,050 mg.L $\mathrm{L}^{-1}$, en aquel entonces). Se realizaron monitoreos de dicho elemento hasta 1998, llegando a la conclusión de cerrar algunos pozos ya que presentaban concentraciones de hasta $1,5 \mathrm{mg} / \mathrm{L}^{-1}$.

Uno de los sistemas para evaluar el daño citogenético que ha demostrado ser versátil y eficiente, es el de las células meristemáticas de la raíz de haba (Vicia faba), debido a que es de fácil manejo, de mantenimiento relativamente económico y que tienen pocos cromosomas [13]. Los cromosomas presentes en haba tienen buen tamaño para realizar un estudio citológico, se distinguen con claridad a un aumento de 40X en su análisis al microscópico; otra de las ventajas para su estudio es que se conocen perfectamente los tiempos de cada una de las etapas de su ciclo celular, siendo la duración total de éstas 19 h y 30 min a $19^{\circ} \mathrm{C}$; aunado a que en los meristemos apicales hay una gran cantidad de células indiferenciadas en división, lo que favorece los estudios de citotoxicidad [5]. El daño genotóxico puede ser de dos tipos, espontáneo e inducido (por factores externos), el primero 
ocurre en los procesos de transmisión y síntesis del DNA para ser expresado como aberraciones, se le denomina Sindependiente, pudiendo ser las alteraciones provocadas del tipo cromatídico y cromosómico; mientras que las alteraciones que requieren pasar por una etapa de síntesis para poder expresarse se les denomina S-dependientes, y son alteraciones del tipo sub-cromatídico. En este trabajo se estudió el daño genotóxico que puede producir como factor externo el arsénico presente en suelos y aguas en la región de Zimapán, utilizando el bioensayo de las células meristemáticas de la raíz de haba.

\section{2 - MATERIAL Y MÉTODOS}

\section{1 - Muestras de aguas}

La caracterización fisicoquímica de las aguas se realizó mediante muestreos sistemáticos y representativos durante un año, para evaluar los niveles medios de concentración de arsénico, recolectada de los diferentes pozos de la población y también del Distribuidor General. El agua utilizada para analizar los daños genotóxicos en Haba fue colectada directamente del Distribuidor General de abastecimiento de la población de Zimapán.

\section{2 - Determinación de arsénico en absorción atómica por generación de hidruros}

En un matraz aforado de $25 \mathrm{~mL}$, se adicionó $1 \mathrm{~mL}$ de yoduro de potasio $5 \%(\mathrm{~m} / \mathrm{m})$ y $1 \mathrm{~mL}$ de ácido ascórbico $5 \%(\mathrm{~m} / \mathrm{m})$ para evitar la oxidación del $\mathrm{KI}$ a $\mathrm{I}_{2}$ y se agitó, posteriormente se adicionó $1 \mathrm{~mL}$ de $\mathrm{HCl}$ concentrado y $10 \mathrm{~mL}$ de la muestra de las digestiones y se aforó. Para la generación de hidruros se preparó una solución de $\mathrm{NaBH}_{4}$ al $0.6 \%(\mathrm{~m} / \mathrm{m})$ en $\mathrm{NaOH}$ al $0.5 \%(\mathrm{~m} / \mathrm{m})$. Para la curva de calibración del equipo se prepararon soluciones de arsénico partiendo de un estándar de As de 1000 ppm diluido a 100 mL (código 571, marca Solutions, Plus Inc.).

\section{3 - Determinación del efecto genotóxico del arsénico en las raíces de Vicia faba}

Se utilizó al haba como un bioensayo para determinar el potencial genotóxico del agua muestreada en Zimapán a través de la inducción de micronúcleos (MNs). Se utilizó haba comercial (Vicia faba variedad minor). Se trataron bajo condiciones especificas para su germinación (humedad, sin luz, y protegidas de polvo).

Se eligieron 20 habas grandes, de tamaño similar y se sumergieron en agua corriente durante 24 horas con el objetivo de reblandecer la testa, al término de este tiempo se observaron las habas un poco más grandes por la hidratación. Se colocaron las habas entre dos capas de algodón en una charola de aluminio, y se humedecieron con agua corriente, sin luz, sin contaminantes (polvo), y lo suficientemente húmedas para favorecer su crecimiento hasta que aparecieron las radículas, posteriormente se quitó la testa para evitar la contaminación por hongos [6].
Cuando las raíces alcanzaron de 4 a $5 \mathrm{~cm}$ de longitud (entre 2 y 3 días) se separaron en 2 lotes, un lote control y el lote problema para su tratamiento. Se eligieron las habas con raíces grandes y se colocaron en la superficie de un vaso de precipitado de $250 \mathrm{~mL}$, cubierto de papel aluminio para evitar la luz, se le hicieron orificios para sumergir sólo las raíces en agua del Distribuidor de abastecimiento de la población de Zimapán, y se dejaron en reposo durante 6 h [7]. Para el lote control negativo se utilizó agua del Municipio de Pachuca. Una vez que ya se trataron las raíces se procedió a la preparación de las laminillas [7, 13]:

- $\quad$ Se cortaron $2 \mathrm{~mm}$ del meristemo apical y se fijaron en una solución de etanol - ácido acético (3:1). Se procedió a la tinción, colocando los meristemos apicales en etanol 70\% (v/v) durante 15 min para deshidratar las células de la raíz y facilitar que penetre mejor el $\mathrm{HCl}$ durante la hidrólisis, la cual fue realizada con $\mathrm{HCl} 5 \mathrm{M}$ durante 30 min. Para eliminar el exceso de $\mathrm{HCl}$ y poder teñir las células, se decantó el $\mathrm{HCl}$ y se lavó 3 veces con agua destilada. La tinción se realizó con aceto-orceína por 40 min y se agregó a los meristemos ácido acético al $45 \%(\mathrm{v} / \mathrm{v})$ con la finalidad de eliminar el exceso de colorante. El aplastamiento en monocapa se realizó luego de la tinción para lo cual se colocó un cubreobjetos y se presionó ligeramente; esto permite que las células no estén unas sobre otras queden lo más dispersas posible para facilitar la observación al microscópico.

La observación al microscopio se realizó en campos al azar contando 1.000 células en interfase para el grupo experimental y para el control. Se determinó por conteos la incidencia de micronúcleos, que muestra el daño genotóxico inducido a través de los rompimientos cromosómicos y cromosomas con el centrómero inactivado y se comparó con un grupo control, analizando las diferencias a través de una prueba de diferencia de proporciones [10].

Para evaluar si el compuesto es más tóxico que mutágeno, se evaluó el daño a través de un índice mitótico, discriminando el número de células en división entre el numero total de células de un conjunto de 1.000 y se comparó con un grupo control, analizando las diferencias a través de una prueba de $\mathrm{X}^{2}[12]$.

\section{3 - RESULTADOS Y DISCUSIÓN}

El efecto genotóxico del Arsénico fue evaluado en las raíces de Vicia faba, tomando este cultivo como un sistema de bioensayo para analizar aberraciones cromosómicas a través de la prueba de micronúcleos, en donde se expusieron las raíces al agua de Zimapán debido a su alto contenido de Arsénico $(0,480 \mathrm{mg} / \mathrm{L})$ para los lotes experimentales, y para los lotes testigos se expusieron bajo las mismas condiciones al agua de Pachuca ( $\sin$ presencia de As, < 0,008 mg/L).

Los MNs son alteraciones observables en anafase, que se originan a través de rompimientos cromosómicos y/o por la falta de segregación de cromosomas debido a una inactivación de su centrómero. En la Figura 1 se muestra un rompimiento de un cromosoma anafásico en haba, inducido 


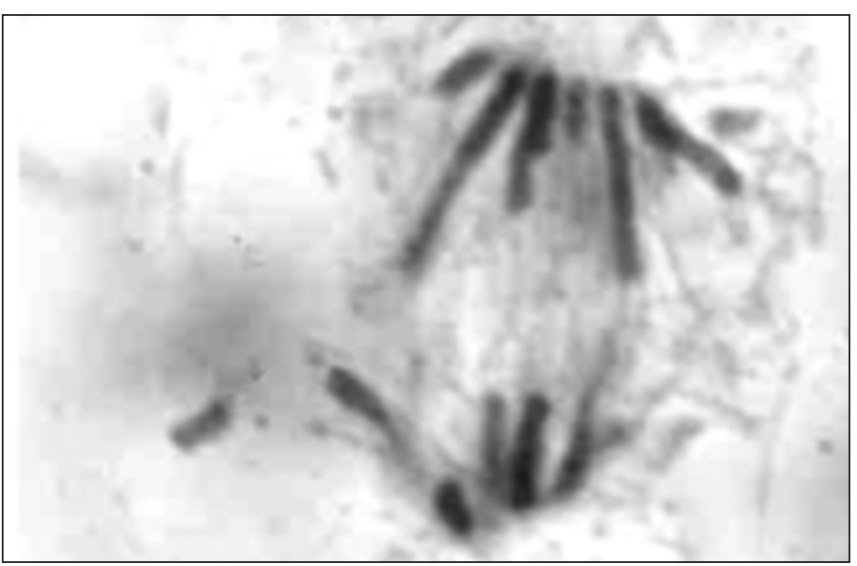

FIGURA 1 - Fragmento cromosómico observable en una anafase de haba el cual se transformará en un MN en telofase

por el tratamiento con el agua de Zimapán a las células meristemáticas de la raíz, el cual es el mecanismo con que el arsénico induce la formación de micronúcleos.

En la Figura $2 A$ se muestra la aparición de micronúcleos inducidos por la presencia de As en las aguas de Zimapán; y como se puede observar al compararlos con la figura $2 B$, es evidente la disminución y/o ausencia de éstos en el grupo control. Estos resultados concuerdan con los encontrados por otros autores [6, 13] al evaluar la inducción de micronúcleos en tejidos vegetales por presencia de agentes xenobióticos como el cromo o insecticidas del tipo carbámicos.

En la Tabla 1 se presenta la frecuencia de células en división, la distribución de éstas por etapa del ciclo celular y el número de MNs encontrados en las muestras control y experimentales. Se puede ver en la tabla y en las microfotografías $2 A$ y $2 B$, que la frecuencia de micronúcleos en los grupos experimentales difiere ligeramente con respecto al grupo control, presentando pequeñas diferencias significativas desde el punto vista estadístico.

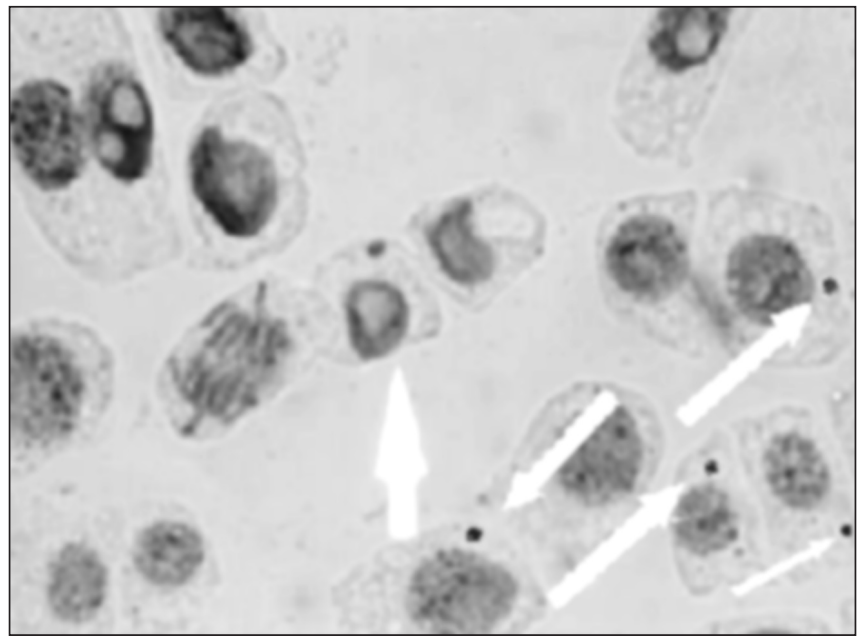

FIGURA 2A - Microfotografía de formación de micronúcleos en raíces de Vicia faba que fueron germinadas en aguas con As. Observados a aumento 40X
TABLA 1 - Frecuencias de células en división y los micronúcleos encontrados en las muestras del grupo control y en el experimental

\begin{tabular}{|c|c|c|c|c|c|c|c|}
\hline & \multirow{2}{*}{$\begin{array}{c}\text { Frecuencias } \\
\text { de células } \\
\text { en división }\end{array}$} & \multicolumn{5}{|c|}{$\begin{array}{l}\text { Células en división por } \\
\text { etapa del ciclo celular }\end{array}$} & \multirow[t]{2}{*}{ Micronúcleos } \\
\hline & & I & $\mathbf{P}$ & $M$ & A & $T$ & \\
\hline Control (sin As) & $55 / 1000$ & $15^{a}$ & $19^{a}$ & $1^{\mathrm{a}}$ & $15^{\mathrm{a}}$ & $4^{a}$ & $1^{\mathrm{a}}$ \\
\hline $\begin{array}{l}\text { Experimental } \\
\text { (con As) }\end{array}$ & $37 / 1000$ & $7^{a}$ & $7^{\mathrm{a}}$ & $4^{a}$ & $4^{b}$ & $4^{a}$ & $11^{\mathrm{b}}$ \\
\hline
\end{tabular}

$\mathrm{I}=$ Interfase, $\mathrm{P}=$ Profase, $\mathrm{M}=$ Metafase, $\mathrm{A}=$ Anafase y $\mathrm{T}=$ Telofase.

Letras diferentes indican diferencias significativas $(p<0,05)$

El resultado anterior pudiera sugerir que no existe un daño genotóxico muy marcado, lo cual puede deberse a que el compuesto sea más tóxico que mutágeno, en donde el efecto mutagénico estuviera encubierto por el efecto tóxico. Para discernir si no hay un efecto genotóxico o hay un efecto citotóxico que encubre la capacidad mutagénica del Arsénico, se evaluó un índice mitótico, que se obtuvo dividiendo el número de células en división entre el total de células observadas y sacando una frecuencia por cada mil células observadas, evaluándose a través de la prueba de $\mathrm{X}^{2}$ [12]. El índice mitótico constituye un criterio para evaluar el daño fisiológico que provoca los diversos agentes xenobióticos. Se ha demostrado que algunas sustancias químicas pueden producir inhibición de la división celular, debido a un efecto citotóxico [1, 3, 4, 8, 13].

De seis preparaciones obtenidas por el grupo control se analizó el número de células en división en mil células por cada una y se promedió dicho resultado. Para el grupo experimental en donde se utilizó el agua de Zimapán, la cual sobrepasa los límites permisibles de Arsénico, se obtuvieron veintiún muestras, de las cuales también se analizaron mil células en cada una y se promedió igual que al grupo control el numero de células en división entre el total de células observadas (Tabla 2).

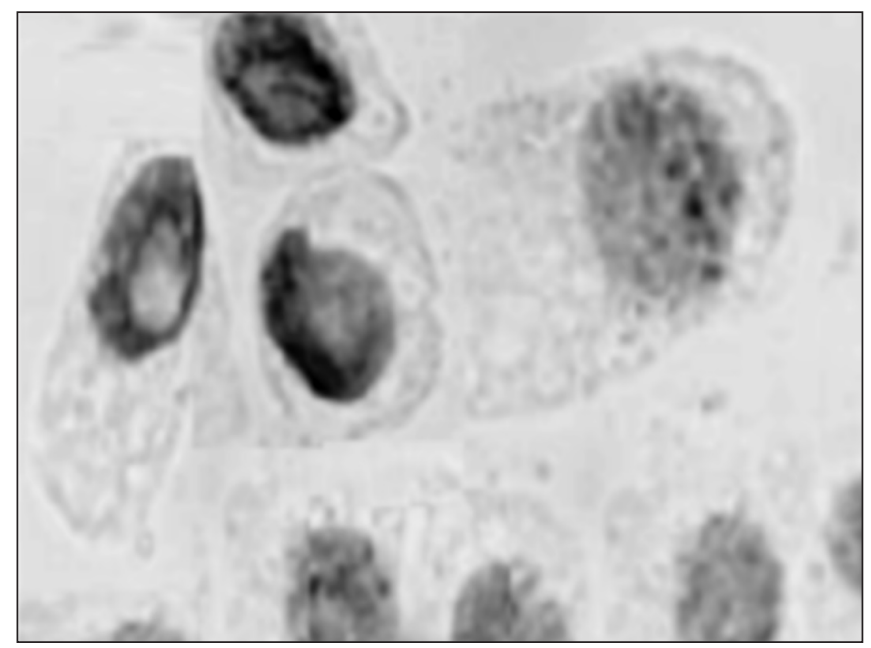

FIGURA 2B - Microfotografía de raíces de Vicia faba que fueron germinadas en aguas sin As. Se puede apreciar la no presencia de micronúcleos. Observado a aumento 40X 
TABLA 2 - Frecuencia de células meristemáticas de Haba en división tratadas con y sin agua contaminada por Arsénico

\begin{tabular}{lccc}
\hline & Células Totales & $\begin{array}{c}\text { Células en } \\
\text { división }\end{array}$ & $\begin{array}{c}\text { Frecuencia } \\
\text { observada }\end{array}$ \\
\hline Control (sin As) & 6000 & 278 & $46 / 1000$ \\
Experimental (con As) & 21000 & 363 & $17 / 1000^{+}$ \\
\hline Positivo (+) , según la prueba de $\mathrm{X}^{2}$, con un $95 \%$ de confiabilidad &
\end{tabular}

Se encontró una reducción de 9,6 veces en la división celular de las muestras tratadas con agua que contiene altas concentraciones de Arsénico con respecto a las muestras del grupo control, como se observa dicha reducción es positiva estadísticamente y capaz de encubrir al efecto mutagénico. Efectos de una sensible reducción en la división celular fueron encontrados igualmente por otros autores [1, 3, 4, 8], en estos casos evaluando la incidencia de radiaciones gamma y/o X o el efecto de aplicaciones de insecticidas [13]. Para determinar si existen diferencias en cuanto a las etapas del ciclo celular observadas en el grupo control y experimental, partiendo de la base de que se ha detectado un efecto citotóxico significativo, se desglosó la frecuencia de aparición de cada una de las sub-etapas de una división y se sacó la frecuencia por cada mil células para tener un índice de comparación.

Como se puede ver en la Tabla 3, no hay diferencias significativas desde el punto de vista estadístico entre el grupo control y el experimental, inicialmente se puede observar que en ambos la mayoría de las células en división están en interfase y profase, existiendo un segundo pico de expresión en anafase, lo que sugiere un comportamiento similar entre los dos grupos y que están coordinadas independientemente del tratamiento. Por ello no se puede saber por el momento, en que lugar al ciclo celular está actuando el efecto citotóxico.

TABLA 3 - Frecuencia observada de células meristemáticas de haba con respecto a cada una de las etapas del ciclo celular en grupos tratados con y sin Arsénico

\begin{tabular}{|c|c|c|c|c|c|c|}
\hline & $\begin{array}{l}\text { Frecuencias } \\
\text { de células }\end{array}$ & Interfase & Profase & Metafase & Anafase & Telofase \\
\hline $\begin{array}{l}\text { Control } \\
\text { (sin As) }\end{array}$ & $46 / 1000$ & 15 & 20 & 1 & 9 & 1 \\
\hline $\begin{array}{l}\text { Experimental } \\
\text { (con As) }\end{array}$ & $17 / 1000^{+}$ & 4 & 6 & 0 & 6 & 1 \\
\hline
\end{tabular}

Se realizó el análisis estadístico por medio de $\mathrm{X}^{2} \mathrm{y}$ se encontró igual número de células en etapas de interfase, profase y anafase para ambos casos, de acuerdo a su proporción.

\section{4 - CONCLUSIONES}

El efecto genotóxico del arsénico en las raíces de Vicia faba, se pudo apreciar desde el inicio al observarse el rompimiento de un cromosoma anafásico y la aparición de micronúcleos inducidos por la presencia de As en las aguas de Zimapán, a diferencia de la ausencia de estos en el grupo control; así también, se observaron las pequeñas diferencias significativas desde el punto vista estadístico. Se encontró además, una reducción de 9,6 veces la división celular de las muestras tratadas con agua que contiene altas concentraciones de arsénico con respecto a las muestras del grupo control, resultando dicha reducción, positiva estadísticamente y capaz de encubrir al efecto mutagénico.

\section{5 - REFERÊNCIAS BIBLIOGRÁFICAS}

[1] BURHOLT D. R.; VAN'T HOFT J. Cell population Kinetic of Pisum root meristem cell during and after a mitotic inhibitory exposure to protracted gamma irradiation, Int J. Radiat Biol., p. 307-319, 1972.

[2] CNA. (1992-1998). Comisión Nacional del Agua (CNA). Gerencia Regional Golfo Norte. Gerencia Estatal en Hidalgo. Metales pesados en fuentes de abastecimiento en el Municipio de Zimapán, Hgo. Informe. Inédito. 1999.

[3] DAVIDSON D. A. Method for estimating mitotic rates in Vicia roots after X irradiation, Brit. J. Radiol, 32, p. 612-664, 1959.

[4] DAVIDSON D. Meristem initial Cell in irradiated roots of Vicia faba, Ann, Bot, 24, p. 287-295, 1960.

[5] EVANS H. J; SCOTT D. Influence of DNA synthesis on the production of cromatid aberrations by X-rays and maleic hydrazide in Vicia faba, Genetics, 49, p. 17-38, 1964.

[6] GÓMEZ A. S.; VILLALOBOS P. Chromosomal alterations induced by some chromiun salt, Cytology, 48, p. 185-193, 1983.

[7] GUZMÁN B. D. P. Evaluación de la frecuencia de micronúcleos en células epiteliales como prueba para detectar exposición crónica al arsénico, Tesis de Maestría, Universidad Nacional Autónoma de México.

[8] HABER A. H.; FORRAD D. E. Further studies of gamma-Irradiated wheat and their relevance to use of mitotic inhibition for developmental studies, AMER J, But, 51, p. 151-159, 1964.

[9] NORMA OFICIAL MEXICANA NOM-127-SSA1-1994. Salud ambiental, agua para uso y consumo humano. Límites permisibles de calidad y tratamiento a que debe someterse para su potabilización. Diario Oficial de la Federación, p. 1103-1139, 18 de enero, 1996.

[10] OBE G. Advances in mutagenesis reseca Berlin Heidelberg, Singer Verleg, New York, USA, 1994.

[11] PÉREZ M. F. Lixiviación y precipitación de arsénico en aguas y lodos de pozos en el distribuidor general de Zimapán, Hidalgo, UAEH, 154 p., Disertación - Tesis Doctoral en Química, Universidad Autónoma del Estado de Hidalgo (UAEH), Pachuca, Hidalgo, México, 2004.

[12] SPIEGEL M R. Theory and problems of stadistics, Schaum, New York, USA, 1970.

[13] VALENCIA Q. P. R. Efecto de los Insecticidas carbamicos Metomil y Oxamil sobre los cromosomas de las células meristematicas de la raíz de Vicia faba, UNAM, Disertación - Tesis de Maestría e Biología, Universidad Nacional Autónoma de México, México, 1992. 